\title{
FIRM DYNAMICS AND GROWTH MEASUREMENT IN FRANCE
}

\author{
Philippe Aghion \\ Collège de France and LSE \\ Timo Boppart \\ IIES, Stockholm University
}

\section{Antonin Bergeaud}

Banque de France

\author{
Simon Bunel \\ INSEE
}

\begin{abstract}
In this paper we use the same methodology as Aghion et al. (2017a) to compute missing growth estimates from creative destruction in France. We find that from 2004 to 2015, about 0.5 percentage point of real output growth per year is missed by the statistical office, which is about the same as what was found in the United States. We look at how missing growth varies across French sectors and regions, and we look at the underlying establishment and firm dynamics. In particular we show that the similar missing growth estimates between France and the United States hide noticeable differences in plant dynamics between the two countries. (JEL: O4)
\end{abstract}

\section{Introduction}

In 1938, economist Alvin Hansen explained in his Presidential Address before the American Economic Association that in his opinion, the United States faced inexorable weak growth in the long term that he denoted "secular stagnation" (Hansen 1939). The nation was just emerging from the Great Depression, and Hansen did not anticipate another World War that would stimulate a rebound in public spending and thereby of aggregate demand. Since then, the world has experienced remarkable growth but also another major crisis in 2007. This "Great Recession" led some economists to revive the expression "secular stagnation" to characterize a situation that they assimilated to

The editor in charge of this paper was Claudio Michelacci.

Acknowledgments: This paper was prepared for Philippe Aghion's Presidential Address at the 2017 EEA Congress in Lisbon. It draws unrestrainedly from our joint work with Pete Klenow and Huiyu Li on Missing Growth in the United States. The paper does not reflect the position of Insee or Banque de France, but only its authors' views. All the results have been reviewed to ensure that no confidential information from the French Statistical Office INSEE has been disclosed. The authors want to thank, without implicating, Didier Blanchet, Hélène Poncet, Nicolas Ragache, Sébastien Roux, and Jean-Luc Tavernier for very helpful suggestions and discussions. Boppart thanks Vetenskaprådet (grant 2016-02194) for financial support.

E-mail: p.aghion@1se.ac.uk (Aghion); antonin.bergeaud@banque-france.fr (Bergeaud); timo.boppart@iies.su.se (Boppart); simon.bunel@insee.fr (Bunel) 